\title{
Uma mulher fascinante à frente de seu tempo: proposta para uma hermenêutica do feminino através das linhas e entrelinhas do Cântico dos cânticos de Salomão
}

\begin{abstract}
A fascinating woman ahead of her time: a hermeneutics' proposal of the feminine through the lines and between rows of The Song of Songs, which is Solomon's
\end{abstract}

Alessandra Serra Viegas

\section{Resumo}

$\mathrm{O}$ presente texto tem o intuito de apresentar uma personagem no mínimo interessante, a partir do discurso imbuído de poesia no Cântico dos cânticos de Salomão: a Sulamita (Ct 7,1)! Uma mulher cujo nome já nos desafia por sua constituição e significado: assim como o nome Salomão, ela é aquela que carrega em si a paz. Ao mesmo tempo, através da proximidade do nome, ela é, também, próxima ao rei: próxima na intimidade apontada no texto, próxima ao ponto de ser sua companheira, uma com ele. Além, disso, essa mulher é negra e bela, camponesa e simples, ousada e trabalhadora de sol a sol (Ct 1,5-6) - mulher forte e preparada pela vida para ser rainha. Que a força dessa poesia que aponta uma mulher quebradora de paradigmas, paradoxalmente não palaciana e cheia de nobreza, nos faça analisar o texto sagrado e a nós mesmos/ mesmas). E que isso seja feito através de uma hermenêutica do feminino 
que, aplicada ao texto, reverbere em nossas relações diárias, a fim de que haja mais afetividade e acolhimento, em nossa própria vida.

Palavras-chave: Cântico dos cânticos. Quebra de paradigmas. Salomão. Sulamita. Hermenêutica do feminino.

\begin{abstract}
This text aims to introduce a character at least interesting, from the speech imbued with poetry in The Song of Songs, which is Solomon's: the Shulamite (Song 7.1)! A woman whose name already challenges us by its constitution and meaning: like the name Solomon, she is the one who carries peace in her. At the same time, through the resemblance of the name, she is also close to the king: close in intimacy in the text, close to the point of being his partner, one with him. In addition, this woman is black and beautiful, peasant and simple, daring and hardworking with sun gazing on her (Song 1.5-6) - a strong woman prepared for life to be queen. May the strength of this poetry that points out a paradigm-breaking woman, paradoxically non-palatial and plenty of nobility, makes us analyze the sacred texts and ourselves. And let this be done through a feminine hermeneutics which, applied to the text, reverts in our daily relationships, so that there may be more affection and acceptance, in our own life.
\end{abstract}

Keywords: Song of songs. Paradigm-breaking. Solomon. Shulamite. Feminine Hermeneutics.

\title{
1. Um texto de puro amor: tradução e trajetória de um verso apenas
}

Iniciamos este texto com uma pergunta para refletirmos juntos a partir de agora: será que já percebemos realmente o que significa a expressão que dá o título ao livro "O Cântico dos cânticos de Salomão"? Em 1Rs 3,9.12, o narrador nos faz observar que "Deus deu a Salomão sabedoria e inteligência extraordinárias e um coração tão vasto como a areia que está na praia do mar.[...] Pronunciou três mil provérbios e seus cânticos foram em número de mil e cinco" (1Rs 5,12). ${ }^{1}$

\footnotetext{
${ }^{1}$ Os textos bíblicos citados seguem a Bíblia de Jerusalém (2017), exceto quando feitas comparações entre as várias traduções em língua portuguesa.
} 
Com esta capacidade dada por Deus, dentre esses mil e cinco cânticos, um foi eleito como o melhor e mais belo cântico de todos, ou, como dizemos em língua portuguesa quando queremos enfatizar um substantivo através do artigo definido - este é $o$ cântico! Esta é a estrutura com semântica superlativa que a expressão hebraica quer nos passar.

É importante também iniciar esse texto que você, leitor, tem em mãos, com a seguinte informação: toda tradução concomitantemente se torna uma interpretação. $\mathrm{O}$ tradutor imprime, no texto traduzido, na maioria das vezes, senão em todas, suas crenças e valores, sua leitura própria de mundo. E isso ganha ainda mais força quando se traz para a língua de chegada uma palavra cujo idioma original tem uma gama de significados.

O que é preciso fazer, então, além de traduzir, a fim de que os vocábulos escolhidos sejam o mais próximo possível do que se traduz? Estudar a fundo a cultura do povo que escreveu o texto, refletir sobre o contexto do que está escrito, tornar-se um arqueólogo das linhas, cavando e descobrindo camadas nas entrelinhas para aí, sim, tentar chegar ao que se quis falar. Ufa!

Nesta busca pela arqueologia das linhas, o Cântico dos cânticos de Salomão nos apresenta uma mulher muito interessante a começar por seu aspecto físico, pela cor da sua pele. Que fique bem claro desde já o quanto essa mulher é formosa e amada, e por isso escolhida pelo rei para estar ao seu lado. Ela é uma bela morena!(?) Pelo menos, morena é o termo escolhido pela maioria das bíblias em língua portuguesa no Brasil para traduzir o adjetivo

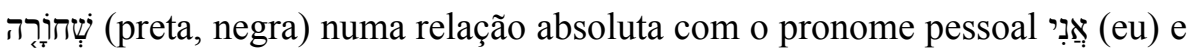
descrevê-la (Ct 1,5).

Note-se, também, além da morenice da moça, a partir de em Ct 1,5a (cujas traduções vemos abaixo) tem dois tipos de tradução para

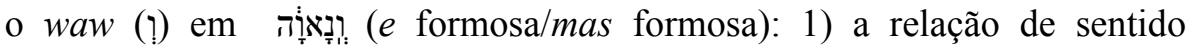
estabelecida pela conjunção coordenativa adversativa - a morena mas/porém formosa/bonita (oposição); 2) a relação estabelecida pela conjunção aditiva a morena $e$ bonita/formosa/bela/agradável (adição):

Sou morena, mas formosa, ó filhas de Jerusalém,... (Bíblia de Jerusalém) Eu sou morena, porém formosa, ó filhas de Jerusalém,... (Almeida Corrigida Fiel)

Eu sou morena, mas sou bonita; ouviram, moças de Jerusalém,... (Bíblia Viva) 
Eu estou morena e formosa, ó filhas de Jerusalém,... (Almeida Revista e Atualizada)

Eu sou morena e bonita, ó filhas de Jerusalém,... (Nova Almeida Atualizada)

Eu sou morena e agradável, ó filhas de Jerusalém,... (Almeida Revista e Corrigida)

Sou morena e bela, ó mulheres de Jerusalém,... (Nova Versão Transformadora)

Apesar da morenice presente nas traduções acima, encontramos três em que a moça tem a pele preta/negra, no entanto continua a problemática da conjunção waw (!), ora traduzida em sentido adversativo (relação de oposição), ora copulativo (relação de adição):

Eu sou negra, porém graciosa, ó filhas de Jerusalém,... (Bíblia King James)

Eu sou preta, mas bela, filhas de Jerusalém,... (Tradução Ecumênica da Bíblia)

Eu sou negra e formosa, ó filhas de Jerusalém,... (Bíblia da Ed. Vozes, 2012)

Não podemos deixar de apontar a Tradução Oficial da CNBB, em que a amada é morena e a conjunção waw (?) não é considerada, pensando à primeira vista. Isto porque, se analisarmos o waw como copulativo (aditivo), é possível ocultar o $e$ na tradução em português, entretanto sem perder o sentido. Eis a tradução:

Sou morena, sou formosa, mulheres de Jerusalém,... (Bíblia Sagrada.

Edições CNBB, 2018)

Elencadas as traduções acima, esta comparação traz no seu bojo pelo menos duas indagações: 1) por que não usar o termo negra/preta em todas as traduções, pois o uso do adjetivo feminino שָׁׁ (negra/preta) dentro da expressão na Bíblia Hebraica (usamos a BHS) é enfático (com o pronome

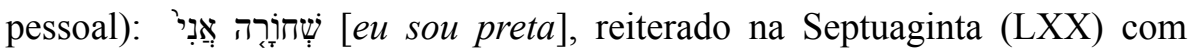

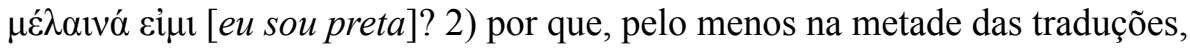
o vocábulo morena/negra causa uma relação de oposição (mas/porém) com bela/formosa/graciosa e não uma relação de adição (e)? Para isso, dentre várias explicações interessantes, trazemos duas registradas na obra de Geraldo 
Cavalcanti, estudioso de Cântico dos cânticos, cada uma tendendo para um lado. Vamos à primeira.

Quanto à pele dessa mulher amada pelo rei, ou seja, introduzida na corte, temos:

Na poesia antiga árabe, a mulher urbana, de classe abastada, era inevitavelmente retratada como de tez alva, diferençando-se, assim, de suas escravas e servas, ou das beduínas, mulheres do campo, de tez mais escura, em virtude de suas origens raciais ou como consequência de exposição ao sol em trabalhos externos. ${ }^{2}$

Note-se que há dois motivos para a pele negra: as origens da própria cor da pele, natural; o fato de estar queimada pelo sol, devido ao trabalho no campo. Ambos nos apresentam abertura de pensamento no contexto históricosocial do Antigo Testamento. Primeiro, sabe-se que Salomão, já rei, casou com a filha do Faraó do Egito (1Rs 3,1). E o Egito está na África, o que aponta muito provavelmente essa princesa, agora rainha, tendo a pele negra ou, no máximo, mulata, se houvera antes de seu nascimento o casamento através de alianças políticas e econômicas entre os povos - de cores de pele diversas nas regiões ao redor do Mediterrâneo à época. Simples assim. Imprescindível lembrar que, na Antiguidade, tais povos não possuíam os preconceitos e racismos que a modernidade trouxe (note-se que o amado é alvo e rosado, $\mathrm{Ct}$ $5,10){ }^{3}$ Até mesmo os gregos tinham intenso comércio e intercâmbios culturais com os povos africanos, bem como casavam entre si para a manutenção de alianças econômico-políticas. ${ }^{4}$

O segundo motivo, não menos importante, é o fato de essa mulher ser uma camponesa, ou seja, essa mulher, muito fora do ambiente da realeza, muito diferente das palacianas, mas de uma firmeza e de uma nobreza incontestáveis em sua postura e palavras, é aquela por quem o rei vai se apaixonar. Uma reflexão relevante advinda deste fato é: a partir do momento em que eu -

\footnotetext{
${ }^{2}$ CAVALCANTI, G. H., O Cântico dos Cânticos, p. 261.

${ }^{3}$ Este é o grande perigo de ler o texto bíblico, escrito na Antiguidade, com os olhos da modernidade. Não podemos em hipótese alguma fazer esse tipo de hermenêutica. O método histórico para o estudo da História Antiga preconiza essa ideia. Para saber mais, veja: BLOCH, M., Apologia da história ou $\mathrm{O}$ ofício de historiador. Em outras palavras, a compreensão, os valores e a leitura de mundo àquela época eram completamente diferentes da atualidade.

${ }^{4}$ Para saber mais sobre as relações entre gregos e africanos, veja SNOWDEN JR, F. M., Before Color Prejudice; SNOWDEN JR, F. M., Blacks in Antiquity; BERNAL, M., Black Athena.
} 
ouvinte-leitor - creio que este texto é palavra de Deus, Escritura Sagrada, o que preciso aprender com essa fala, essa questão, esse amor, essa mulher? Qual é a intencionalidade do autor? Consigo alcançá-la?

O melhor e mais belo cântico tem a sua autoria tradicionalmente atribuída a um rei sábio - Salomão ${ }^{5}$ e nos mostra um amor surgido em Jerusalém de uma quebra de paradigmas: a amada e tão formosa tem a pele queimada de sol, é trabalhadora do campo, pertence a uma família numerosa, é obrigada a cuidar das vinhas dos irmãos. Não tem tempo para cuidar de si porque precisa ajudar aos outros. Moça bastante madura e diferenciada, sem tempo para futilidades e com uma sabedoria adquirida pelos enfrentamentos e adversidades da vida desde cedo. Essa é $a$ moça. Como não amá-la?

Seguindo, vamos à segunda explicação, que Cavalcanti traz a partir da Patrística:

Para Orígenes, as palavras da Sulamita são uma resposta da Igreja, religião de gentios, à Sinagoga, que se considerava superior por sua origem mosaica: Sou negra, sim, por minha origem humilde, mas sou bela por minha penitência e por minha fé. ${ }^{6}$

Pensar em uma beleza autêntica em sua naturalidade e singeleza, associada à penitência e à fé, como também à humildade, é pensar ao mesmo tempo em uma nobreza que nos aproxima da simplicidade ensinada pelas palavras, vida, morte e ressurreição do próprio Jesus Cristo, demonstradas no evangelho a que nós, cristãos, como Igreja, seguimos. A gentilidade na origem daquele que não se acha digno de ser amado e aceito, a pobreza de espírito que se torna porta de entrada no Reino dos Céus (Mt 5,3) para aquele que se considera um pedinte ${ }^{7}$ e em tudo depende de outrem, de Jesus, para adentrar esta porta é exatamente o que o leva até ela. Eis a beleza que atrai ao rei! ${ }^{8}$

\footnotetext{
${ }^{5}$ MALANGA, E. B., A Bíblia Hebraica como Obra Aberta, p. 318: As frequentes menções ao rei, a Salomão, a palácios e riquezas tanto podem ser meramente um recurso estilístico quanto indicar um tipo de poema da nobreza.

${ }^{6}$ Apud POPE, M. H., The Song of Songs, p. 309-310.

${ }^{7} \mathrm{O}$ texto grego de Mateus 5,3 traz o vocábulo $\pi \tau \omega \chi \mathbf{o} \varsigma$, cujo significado vai além daquele que é pobre: miserável, mendigo, impotente.

${ }^{8}$ Segundo a nota da Bíblia edição da família, p. 817, por Luís Stadelmann: "Ante os olhares inquisitivos das companheiras, que parecem indagar-se como a Sulamita, de condição social inferior, pôde merecer a predileção do seu amado, ela afirma os atrativos de sua beleza feminina, explicando sua tez morena como reflexo da vida de trabalho, que não lhe permite tratamentos de beleza".
} 


\section{Amor forte como a morte: poesia e ousadia}

Como um livro de cânticos e, portanto, de poemas que é, o melhor dos cânticos de Salomão é pura música de elogio ao amor (cântico de amor e matrimônio ${ }^{9}$ ), em que a amada, o amado e o coro cantam. São várias as características da poesia hebraica ao longo dos poemas e eram elas que ficavam na memória do povo que ouvia o cântico. Isto porque a poesia hebraica traz uma espécie de "rima de assuntos", isto é, o paralelismo de ideias, com palavras e expressões sinônimas ou idênticas, além dos refrãos, ao longo dos poemas, a fim de serem lembrados, bem como o coro, trazendo questionamentos. Vejamos alguns trechos seletos que apresentam tais características que são identificadas facilmente (com as marcações):

\section{Paralelismo:}

Que beleza tuas faces entre os brincos, teu pescoço, com colares! $(1,10)$

As vigas de nossa casa são de cedro, o seu teto, de ciprestes. $(1,17)$

Sou o narciso de Saron, o lírio dos vales. $(2,1)$

Como açucena entre espinhos é minha amada entre as donzelas. Macieira entre as árvores do bosque, é meu amado entre os jovens; (2,2-3a-b)

\section{Refrãos:}

Como és bela, minha amada, como és bela ${ }^{10}$ !... $(1,15 ; 4,1)$

\footnotetext{
${ }^{9}$ Para Milton Schwantes, pensar no Cântico como um cerimonial de casamento é ter boas intenções que nada tem a ver com o capítulo 8 (objeto de sua pesquisa no texto Debaixo da macieira: Cantares à luz de Ct 8,5-14): "Ela [a poesia] não era usada em cerimônias de casamento, e se ler todo Cantares, verá que nem se adapta ao ritual matrimonial” (SCHWANTES, M., Debaixo da macieira, p. 43).

${ }^{10}$ Note-se a repetição de "como és bela", bem como a utilização da sinonímia no paralelismo em "cervas... gazelas" e em "não acordeis, nem desperteis" nos próprios refrãos, com a finalidade de memorização dos ouvintes-leitores.
} 
Filhas de Jerusalém,

pelas cervas e gazelas do campo,

eu vos conjuro:

não desperteis, não acordeis o amor,

até que ele o queira! $(2,7 ; 3,5 ; 8,4$ - este último suprime "pelas cervas e gazelas do campo")

3. Coro em forma de questionamentos:

Que é aquilo que sobe do deserto, como colunas de fumaça perfumada com incenso e mirra, e perfumes dos mercadores? $(3,6)$

Que é teu amado mais que os outros, ó mais bela das mulheres?

Que é teu amado mais que os outros, para assim nos conjurares? $(5,9)$

Quem é essa que sobe do deserto apoiada em seu amado? $(8,5)$

Além dessas características que passeiam ao longo do cântico, os assuntos vão se diversificando ao longo dos "capítulos", de modo que se formam dez poemas na estrutura apresentada na Bíblia de Jerusalém. São eles: 1,5-2,7; $2,8-17 ; 3,1-5 ; 3,6-11 ; 4,1-5,1 ; 5,2-8 ; 5,9-6,3 ; 6,4-10 ; 6,11-7,11 ; 7,12-8,4$ (1,1-4 compõe o prólogo, 8,5-7 o epílogo e 8,8-14 os apêndices). Já para Milton Schwantes, temos cinco poemas assim distribuídos: (1,1-4 compõe o prólogo) $1,5-2,7 ; 2,8-3,5 ; 3,6-5,8 ; 5,9-8,4 ; 8,5-14 .{ }^{11}$ Por sua diversidade de subtemas sobre o tema principal do amor que perpassa todo o cântico, o exame acurado do texto deixa nítido que não se trata de um único poema, mas de uma pequena coletânea reunindo alguns poemas de amor. ${ }^{12}$

Fora do Cântico dos cânticos, o único texto que poderíamos aproximar um pouco em sua forma ${ }^{13}$ é o Salmo 45 e dispô-los sob o gênero literário do

\footnotetext{
${ }^{11}$ SCHWANTES, M., Debaixo da macieira, p. 41. O argumento principal, para Schwantes, é a presença do refrão com as filhas de Jerusalém abrindo e/ou fechando cada um dos poemas.

${ }^{12}$ MALANGA, E. B., A Bíblia Hebraica como Obra Aberta, p. 318.

${ }^{13}$ LIMA, M. L. C., Exegese bíblica, p. 123: a forma é a apresentação particular de um texto, a organização de seus diversos elementos. Quanto a casamento, veja-se a nota 10.
} 
canto de amor e casamento. ${ }^{14}$ Um gênero literário é constituído partindo-se da existência de dois ou mais textos que apresentem características semelhantes entre as quais se possa estabelecer uma comparação. ${ }^{15}$ Entretanto, a ousadia apresentada pelas falas dos amantes no Cântico não ocorre em nenhum outro trecho da bíblia.

Por este motivo, a falta de escritos semelhantes que estabelecessem um padrão fez com que o Cântico dos cânticos se tornasse enigmático e com muitas possibilidades de leitura, inclusive as alegóricas pelas quais o texto é mais conhecido, apresentando o amado como o noivo/esposo YHWH e a amada como a noiva/esposa povo de Israel, no Antigo Testamento, ou o amado como o noivo Jesus e a amada como a noiva Igreja, no Novo Testamento. A "estranheza" causada pela descrição de emoções e atitudes dos amantes ao longo do texto levou-o à abertura interpretativa, ${ }^{16}$ possibilitando diversas chaves de leitura, bem como diversas hermenêuticas.

Ainda, quanto à datação, algumas problemáticas se apresentam: ${ }^{17}$ por um lado, sua redação é situada à época da monarquia, em razão da influência literária egípcia ${ }^{18}$ (por rotas de comércio e alianças políticas por casamentos), bem como devido às referências geográficas, como a menção de Tersa, que foi a capital do reino do Norte (Israel) até 880 a.C. Por outro lado, tais dados não são suficientes para situar o texto no período da monarquia, tampouco atribuir a autoria a Salomão. Por suas características linguísticas, o texto pode ser situado no retorno do exílio babilônico, no período persa, embora haja quem prefira datá-lo no século III a.C., no período de domínio helenístico, após as conquistas de Alexandre Magno, tempo em que há uma grande miscelânea e intercâmbios culturais presentes nas sociedades em torno do Mediterrâneo.

Com a ousadia que lhe é peculiar, o poema tem um ritmo acelerado e leve, com frases curtas, cheias de descrições elogiosas de um dos amantes acerca do outro. ${ }^{19} \mathrm{O}$ amado utiliza comparações e metáforas ${ }^{20}$ para descrever a beleza corporal da amada porque a ama como ela é e a elogia - citando partes

\footnotetext{
${ }^{14}$ LIMA, M. L. C., Exegese bíblica, p. 183.

${ }^{15}$ LIMA, M. L. C., Exegese bíblica, p. 123.

${ }^{16}$ MALANGA, E. B., A Bíblia Hebraica como Obra Aberta, p. 318.

${ }^{17}$ MALANGA, E. B., A Bíblia Hebraica como Obra Aberta, p. 317.

${ }^{18}$ Literariamente, o estilo do cântico remete ao dos poemas de amor do Egito.

${ }^{19}$ MALANGA, E. B., A Bíblia Hebraica como Obra Aberta, p. 318.

${ }^{20}$ A diferença básica entre essas duas figuras de linguagem é simples: ambas estabelecem comparações, entretanto a comparação utiliza a conjunção como e a metáfora não a utiliza.
} 
de seu corpo de cima para baixo (Ct 4,1-5.7-15) e de baixo para cima (Ct 7,26), simetricamente. ${ }^{21}$ Vejamos alguns trechos seletos que apresentam:

\author{
1. Comparações: \\ Teu nariz, como a torre do Líbano, \\ voltada para Damasco; \\ tua cabeça que se alteia como o Carmelo, \\ e teus cabelos cor de púrpura, \\ enlaçando um rei nas tranças. $(7,5 \mathrm{~d}-6)$
}

\title{
2. Metáforas:
}

Teu umbigo...essa taça redonda em que o vinho nunca falta; teu ventre, monte de trigo rodeado de açucenas; teus seios, dois filhotes, filhos gêmeos de gazela; teu pescoço, torre de marfim; teus olhos, as piscinas de Hesebon, junto às portas de Bat-Rabim. (7,3-5c)

A amada também fala ousada e abertamente da beleza do corpo do seu amado em detalhes, com um movimento totalmente diferente: aspecto geral $\rightarrow$ cabeça $\rightarrow$ braços $\rightarrow$ ventre $\rightarrow$ pernas $\rightarrow$ aspecto geral $\rightarrow$ boca $\rightarrow$ totalidade:

Meu amado é branco e rosado, saliente entre dez mil.

Sua cabeça é ouro puro, uma copa de palmeira seus cabelos, pretos como o corvo.

Seus olhos... são pombas

à beira de águas correntes:

banham-se no leite e repousam na margem.

Suas faces são canteiros de bálsamo, colinas de ervas perfumadas;

${ }^{21} \mathrm{O}$ elogio de 7,2-6 começa pelos pés porque inicia na dança de 7,1 . 
seus lábios são lírios

com mirra, que flui

e se derrama.

Seus braços são torneados em ouro

incrustado com pedras de Társis.

Seu ventre é bloco de marfim

cravejado com safiras.

Suas pernas, colunas de mármore

firmadas em bases de ouro puro.

Seu aspecto é o do Líbano

altaneiro, como um cedro.

Sua boca é muito doce...

Ele todo é uma delícia!

Assim é o meu amigo,

assim o meu amado,

ó filhas de Jerusalém. (Ct 5,10-16)

Curiosamente, os cabelos do amado são "pretos como o corvo" e o vocábulo pretos é o mesmo utilizado para a pele da amada na sua própria descrição em $\mathrm{Ct}$ 1,5. Para mostrar o prazer que tem ao descrever o amado, Ct 5,16a-b, que dá início ao encerramento da seção, traz: "Sua boca é muito doce... Ele todo é uma delícia!".

Essa mulher que fala às filhas de Jerusalém que seu amado é uma delícia tem a liberdade de quem cantaria hoje um verso da canção Volta prá mim do grupo Roupa Nova: "eu te amo e vou gritar pra todo mundo ouvir", ${ }^{22}$ sem se preocupar com quem está ouvindo. A liberdade de se expressar em amor, a certeza da cumplicidade do amado e o sentimento de pertença na relação que a leva a dizer "Eu sou do meu amado, seu desejo o traz a mim" $(\mathrm{Ct} 7,11)$ pode propositadamente anular a maldição que foi proferida sobre a mulher em Gn 3,16 , na qual seu desejo pelo homem é respondido com dominação. ${ }^{23}$ Será?

\section{O amor jamais acaba: uma hermenêutica do feminino livre}

Ao apresentar os tipos de abordagem bíblico-teológica de mulheres, visando à sua hermenêutica, Marie-Theres Wacker aponta a circunscrição do que Carolyn Osiek cunhou como a "hermenêutica da lealdade":

${ }^{22}$ ROUPA NOVA. Volta pra Mim. C. Horsth, R. Feghali. [Compositores].

${ }^{23}$ SCHOTTROFF, L.; SCHROER S.; WACKER, M-T., Exegese feminista, p. 116. 
Nas Escrituras, embora de forma ligada e "acomodada" aos respectivos tempos e suas pessoas, seria comunicada a ordem de criação e redenção determinada por Deus. Nessa ordem cabem lugares específicos aos homens e às mulheres, mas absolutamente não de níveis qualitativos diferentes. ${ }^{24}$

Ousaria chamar essa hermenêutica da lealdade de hermenêutica da paridade, ou hermenêtica do feminino livre, em que o feminino seja lido e interpretado conforme surge nas vozes do texto bíblico, deixando a Sagrada Escritura falar por si, e não conforme o pensamento do hermeneuta. Ainda citando Wacker, o problema da discriminação de mulheres biblicamente legitimadas não está na própria bíblia, mas exclusivamente em sua interpretação. ${ }^{25} \mathrm{Ou}$, ainda, em sua superinterpretação, como diria Umberto Eco, ${ }^{26}$ ignorando o chão em que o caminho do texto é escrito, falando com uma voz mais alta que a do próprio texto.

A voz feminina dessa mulher amada/amante tão presente no Cântico dos cânticos de Salomão divide a cena e a fala com a voz masculina do amado/ amante. Se fizermos uma leitura cuidadosa e atenta desta poesia, é nítida a percepção de que uma voz não sobrepuja a outra, seja na quantidade ou na qualidade da fala. ${ }^{27}$ Ambas as vozes são, ainda, intercaladas por um coro feminino composto pelas filhas/moças/mulheres de Jerusalém, convidadas à cena e à canção desde o seu início $(\mathrm{Ct} 1,5)$ e continuam sendo as interlocutoras durante todo o cântico (Ct 2,7; 3,5.11 [filhas de Sião]; 5,8.16; 8,4). Note-se, ainda, que o amado nunca se refere a elas, somente a voz feminina o faz.

Outros momentos do Cântico chamam a atenção por introduzirem mais personagens femininas: a mãe de Salomão (Bate-Seba) é quem lhe põe a coroa "no começo da grande alegria do seu coração" (Ct 3,11); a amada imagina como ela leva seu amado à casa de sua mãe $(\mathrm{Ct} 3,4 ; 8,2)$ e não a de seu pai. A figura da mãe - e não a do pai - surge em outras situações (Ct 1,6; 6,9; 8,1). Estes elementos internos, unidos a outros já vistos ao longo desta pesquisa, podem nos apontar uma autoria em grupo misto: homens e mulheres, ou nos fazer corroborar o pensamento de Athalya Brenner quanto à autoria feminina

${ }^{24}$ SCHOTTROFF, L.; SCHROER S.; WACKER, M-T., Exegese feminista, p. 39-40.

${ }^{25}$ SCHOTTROFF, L.; SCHROER S.; WACKER, M-T., Exegese feminista, p. 40.

${ }^{26}$ Para saber mais, dois livros de Umberto Eco tratam do assunto: ECO, U., Interpretação e superinterpretação; e ECO, U., Os limites da interpretação.

${ }^{27}$ Athalya Brenner (BRENNER, A., A mulher israelita) apresenta a distribuição das vozes para nós: em 53\% do texto temos voz(es) feminina(s); em 34\% voz(es) masculina(s); os restantes $13 \%$ são formados pelos coros (6\%) ou são títulos ou casos dúbios (7\%). 
do Cântico: ele proporciona a possível evidência com referência a mulheres escritoras; contém sequências narrativas de experiências reais e arquetípicas; e sua personagem principal é uma mulher. ${ }^{28}$

A partir destas constatações, permite-se a liberdade da voz feminina passeando pelo texto, envolvendo o ouvinte-leitor com esse universo - seja nas falas da própria amada, seja nas referências a ela dadas pelo amado. Pensar em uma hermenêutica do feminino em um texto em que é tão presente este elemento é simplesmente deixar o texto falar por si. A voz feminina é identificada, é presente, é livre. Além disso, a paridade é demonstrada na união homem-mulher, através de um amor que se mantém aceso por meio dos elogios que ambos se dedicam a fazer um ao outro.

A questão para estudar/analisar/refletir sobre o texto do Cântico dos cânticos não é o fato de trazer uma hermenêutica do masculino ou do feminino, como se ambos se digladiassem. É, sim, perceber, na força da paridade presente, a liberdade e a leveza que o texto abarca, seja na ousadia ou na sinceridade das palavras na imagética - da denotação, na beleza nua $e$ crua dos amados/amantes; ou da conotação, nas metáforas empregadas para o rosto, o corpo, a elegância e os gestos de cada um.

Assim como o percurso do reconhecimento ${ }^{29}$ ocorre em Gênesis, quando

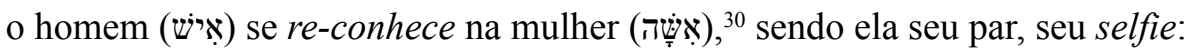
"Esta, sim, é osso de meus ossos e carne de minha carne!" (Gn 2,23) não temos, na paridade e no encontro do melhor dos cânticos de Salomão uma releitura desse percurso? A cada elogio feito à noiva/esposa/amada não reconhece o homem nela, ele mesmo? Também o que ele precisa para o gozo da e na vida (Ecl 9,9), para ser bem-aventurado e próspero (S1 128,1.3-4), encontrando um verdadeiro presente dado por YHWH (Pr 18,22)?

Se a amada/amante, mulher forte e corajosa, que não tem vergonha de ficar nua, literal e figurativamente diante do amado/amante, por que temos nós medo de enfrentar nossa própria vulnerabilidade, ${ }^{31}$ qualidades e defeitos e

\footnotetext{
${ }^{28}$ BRENNER, A., A mulher Israelita, p. 62.

${ }^{29}$ Utilizamos aqui a expressão "percurso do reconhecimento" com base no livro de Paul Ricoeur (RICOEUR, P., Percurso do reconhecimento), que apresenta as relações de identidade e alteridade como uma necessidade humana, partindo da premissa de que não há identidade sem alteridade, ou seja, o eu não pode ser identificado sem o tu.

${ }^{30}$ A tradução revista e corrigida de Almeida em português brasileiro é a que mais se aproxima do texto hebraico que, na formação das palavras, demonstra a semelhança e a paridade entre o שיָָ e traduzindo-os como varão e varoa.

${ }^{31}$ Utilizamos a palavra vulnerabilidade aqui conforme Brené Brown apresenta o resultado de
} 
nos entregarmos, mostrando exatamente quem somos? O melhor dos cânticos de Salomão quer nos ensinar que o amor só acontece quando me aceito e me amo, quando me elogio e me permito ser elogiado/a por outrem porque me conheço e me reconheço, quando tenho a coragem para me lançar na jornada do amor próprio mesmo demonstrando meus defeitos para, aí sim, amar meu próximo e amar a Deus!

Não foi assim com Isaías? Quando ele, em seu chamado como profeta de YHWH, enxergou-se e se aceitou, ele enxergou também YHWH na sua glória - o SENHOR dos Exércitos, no seu alto e sublime trono, permitiu-se ser visto pelo frágil homem que tinha questões com o seu falar (Is 6,1-8). Deixando sua vulnerabilidade e sua vergonha aparecer, teve-as tratadas, e se tornou forte o suficiente para aceitar o mandado de YHWH. Aceitando-se, aceitou o SENHOR. Aceitou o que o SENHOR tinha para sua vida: um caso de amor com o ministério profético - aquilo pelo que valeu a pena viver, nunca sozinho, mas sempre acompanhado pela presença e pela palavra de YHWH.

\section{Conclusão: a mulher de Cantares e um desafio de amor diário}

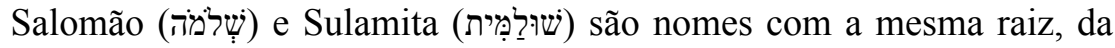
qual também se deriva Shalom (שָׁi்), isto é, presença contínua/completude de paz, prosperidade, alegria, contentamento com aquilo que se possui. Em uma tradução que utilize uma única palavra para descrever quem são esse homem e essa mulher próximos e pares, temos pacificadores. A própria Sulamita parece descrever-se no apêndice quando diz: "sou aquela que encontrou a paz" $(\mathrm{Ct}$ 8,10c-d). Quanto ao cerne do aspecto semântico do prazer e satisfação que o vocábulo hebraico traz, encontramos semelhança no texto (grego) do Novo Testamento - podemos comparar com o segredo/sentimento do aprendizado do apóstolo Paulo para suportar todas as situações e vicissitudes da vida terrena:

Aprendi a adaptar-me às necessidades; sei viver modestamente, e sei também como haver-me na abundância; estou acostumado com toda e

doze anos de suas pesquisas sobre relacionamentos no livro BROWN, B., A Coragem de ser imperfeito. A autora apresenta a vulnerabilidade como elemento essencial nas relações interpessoais, principalmente com os mais próximos, familiares, amigos, bem como no local de trabalho. Segundo ela, quem não tem a ousadia de mostrar realmente quem é e enfrentar a vergonha, seja esta qual for, tornar-se-á escravo e será engolido pela própria vergonha e frustrações. 
qualquer situação: viver saciado e passar fome; ter abundância e sofrer necessidade. Tudo posso naquele que me fortalece (Fp 4,11b-13).

Essa completa paz presente na relação baseada no respeito mútuo e na paridade é a base para o namoro, noivado, casamento, quiçá para a amizade, a maternidade, a paternidade, bem como outras relações com menos intimidade de que homem e mulher façam parte. Assim, em suas falas, a Sulamita e o amado/amante nos desafiam por mostrar uma mulher que tem voz e vez ao lado do homem. Ela/ele sabe quem é e o valor que possui. Ambos se percebem. Ambos se respeitam. Ambos se amam. E isto com amor ao outro e amor próprio, pois como diz o adágio popular: "ninguém pode dar o que não tem". Nesse sentido, pelo aspecto do feminino, o livro de Provérbios entre os capítulos 10-30 e a coleção de cânticos de amor no Cântico dos cânticos se oferecem a nós como fontes valiosas quando queremos conhecer a imagem ou a autoimagem das mulheres israelitas ${ }^{32}$ que os textos querem nos transmitir.

Não se pode deixar de falar quão importante é pensar que "o amor entre o homem e a mulher constitui o caminho para a renovação e a manutenção da esperança de vida para o futuro do mundo". ${ }^{33}$ Em tempos de pessoas que preferem adotar animais a terem filhos, viverem sós a constituírem família; terem relacionamentos desgastados pela presença de tantas informações trazidas pela tecnologia através da internet, serem casais nos restaurantes comendo juntos ao mesmo tempo em que não se olham, mas têm os olhos, sim, fixos cada um ao seu próprio smartfone, é preciso saber que o amor é forte como a morte $(\mathrm{Ct} 8,7)$, pois o amor tem poder invencível, tem caráter fatal, tem valor sem igual!

Urge permitir que o amor se revele a nós e nos invada, ${ }^{34}$ como diz um de nossos cânticos da música popular brasileira. A leitura do melhor e mais belo cântico de Salomão precisa ser entendida, interpretada (e principalmente assimilada) pelas três metáforas utilizadas na introdução à hermenêutica bíblica de Jean-Louis Ska: como espelho, lâmpada e janela. ${ }^{35}$ Espelho, para nos vermos refletidos neste texto de amor e tomarmos posição diante dele;

32 SCHOTTROFF, L.; SCHROER, S.; WACKER, M-T., Exegese feminista, p. 116. Para a pesquisadora, estes textos teriam surgido nos séculos VIII-VI a.C.

${ }^{33}$ SIQUEIRA, T. M., Em memória do amor, p. 27.

${ }^{34}$ Referimo-nos aos últimos versos da canção Pétala, de Djavan: "por ser exato, o amor não cabe em si / por ser encantado, o amor revela-se / por ser amor, invade e fim”. DJAVAN. Pétala. Djavan [Compositor].

${ }^{35}$ SKA, J-L., Specchi, lampade e finestre, p. 37-68. 
lâmpada, para que essa leitura nos ilumine e nos faça pensar; janela, para que abra nossa mente e nos faça ler o mundo a partir desse amor. E que, a partir de então, possamos colocá-lo em prática nas atividades mais simples e corriqueiras da vida diária. E nas mais elaboradas e complexas também.

Que tal começar se olhando no espelho agora mesmo, você, leitor ou leitora, e se elogiando? Não importa se sua pele é branca, negra ou queimada de sol. Não importa se você tem menor ou maior poder aquisitivo. Importa que você é importante (assim com pleonasmo mesmo)! Dispa-se diante do espelho. Dispa-se em corpo, alma e espírito. Este é o desafio da Sulamita! Que nos permitamos ser desafiados diariamente por esta mulher em nosso relacionamento conosco mesmos/mesmas, com nosso(s) próximo(s), com Deus. Conforme diz mais um de nossos cânticos da atualidade: "É preciso amar as pessoas [você é uma delas] como se não houvesse amanhã". ${ }^{36}$

\section{Referências bibliográficas}

A BÍBLIA Viva. 2.ed. São Paulo: Mundo Cristão, 2002.

BERNAL, M. Black Athena: The Afroasiatic Roots of Classical Civilization. New Jersey: Rutgers University Press Classics, 2020.

BÍBLIA. Tradução Ecumênica da Bíblia. São Paulo: Loyola, 1984.

BÍBLIA de Estudo John Wesley. Nova Almeida Atualizada. 1.ed. São Paulo: SBB, 2020.

BÍBLIA de Estudo King James. 1.ed. revis. Rio de Janeiro: BV Books, 2018. BÍBLIA de Estudo Pentecostal. Almeida Revista e Corrigida. 4. imp. Flórida: CPAD, 1997.

BÍBLIA de Jerusalém. Nova edição, revista e ampliada. 2.ed. 12. reimp. São Paulo: Paulus, 2017.

BÍBLIA de Referência Thompson. Almeida Corrigida Fiel. 3. imp. Flórida: Vida, 1994.

BÍBLIA Sagrada. Edição da Família. 51.ed. Petrópolis: Vozes, 2012.

BÍBLIA Sagrada. Nova Versão Transformadora. 1.ed. São Paulo: Mundo Cristão, 2016.

${ }^{36}$ Trecho da canção Pais e Filhos, do grupo Legião Urbana. LEGIÃO URBANA. Pais e Filhos. M. Bonfá, D. Villa-Lobos, R. Russo. [Compositores]. 
BÍBLIA Sagrada. Tradução Oficial da CNBB. 1.ed. Brasília: CNBB, 2018. BÍBLIA Shedd. Almeida Revista e Atualizada. 2.ed. São Paulo: Vida Nova, 1997.

BLOCH, M. Apologia da história ou O ofício de historiador. Rio de Janeiro: Zahar, 2001.

BRENNER, A. A Mulher Israelita: Papel Social e Modelo Literário na Narrativa Bíblica. São Paulo: Paulinas, 2001.

BROWN B. A Coragem de ser imperfeito: como aceitar a própria vulnerabilidade, vencer a vergonha e ousar ser quem você é. Rio de Janeiro: Sextante, 2019.

CAVAlCANTI, G. H. O Cântico dos Cânticos: um ensaio de interpretação através de suas traduções. São Paulo: EdUSP, 2005.

DJAVAN. Pétala. Djavan [Compositor]. In: DJAVAN. Pétala. [S.1.]: Sony Music, 1988. 1 LP (ca. 105 min). Faixa 1 (4 min 42 s).

ECO, U. Interpretação e superinterpretação. São Paulo: Martins Fontes, 2005.

ECO, U. Os limites da interpretação. São Paulo: Perspectiva, 2015.

ELliGER, K.; RUDOLPH, W. (Eds.). Biblia Hebraica Stuttgartensia. Stuttgart: Deutsche Bibelgesellchaft, 1990.

LEGIÃO URBANA. Pais e Filhos. M. Bonfá, D. Villa-Lobos, R. Russo. [Compositores]. In: LEGIÃO URBANA. As Quatro Estações. [S.1.]: Emi, 1989. 1 LP (ca. $47 \mathrm{~min})$. Faixa 2 (5 min $8 \mathrm{~s}$ ).

LIMA, M. L. C. Exegese bíblica: teoria e prática. São Paulo: Paulinas, 2014.

MALANGA, E. B. A Bíblia Hebraica como Obra Aberta. São Paulo: Humanitas-FAPESP, 2005.

POPE, M. H. The Song of Songs: a New Translation with Introduction and Commentary. New York: Doubleday \& Company, 1977. (The Anchor Bible, 7C).

RAHLFS, A.; HANHART, R. (Eds.). Septuaginta. Stuttgart: Deutsche Bibelgesellschaft, 1979.

RICOEUR, P. Percurso do reconhecimento. São Paulo: Loyola, 2006.

ROUPA NOVA. Volta pra Mim. C. Horsth, R. Feghali. [Compositores]. In: 
LEGIÃO URBANA. Herança. [S.1.], 1987. 1 LP (ca. 48 min). Faixa 1 (4 min $14 \mathrm{~s})$.

SCHWANTES, M. Debaixo da macieira: cantares à luz dos Cantares 8,5-14. Estudos Bíblicos, n. 40, p. 39-49, 1993.

SIQUEIRA, T. M. Em memória do amor. Estudos Bíblicos, n. 40, p. 24-29, 1993.

SKA, J-L. Specchi, lampade e finestre: introduzione all'ermeneutica bíblica. Bologna: EDB, 2014.

SCHOTTROFF, L.; SCHROER S.; WACKER, M-T. Exegese feminista: resultados de pesquisas bíblicas na perspectiva de mulheres. São Leopoldo: Sinodal 2008.

SNOWDEN JR, F. M. Before Color Prejudice: The Ancient View of Blacks. Cambridge / Massachusetts: Harvard University Press, 1991.

SNOWDEN JR, F. M. Blacks in Antiquity. Cambridge/Massachusetts: Belknap Press, 2005.

\author{
Alessandra Serra Viegas \\ Doutora em Teologia pela Pontifícia Universidade Católica \\ do Rio de Janeiro \\ Doutora em História Comparada pela Universidade Federal \\ do Rio de Janeiro \\ Rio de Janeiro / RJ - Brasil \\ E-mail: aleviegas33@yahoo.com.br
}

Recebido em: 20/10/2021

Aprovado em: 09/12/2021 